\title{
Meteorological Conditions at Racetrack Playa, Death Valley National Park: Implications for Rock Production and Transport
}

\author{
RALPH D. LORENZ,* BRIAN K. JACKSON, ${ }^{+}$JASON W. BARNES, ${ }^{\#}$ JOSEPH N. SPITALE, ${ }^{@}$ \\ JANI RADEBAUGH, ${ }^{\&}$ AND KEVIN H. BAINES*** \\ * Applied Physics Laboratory, The Johns Hopkins University, Laurel, Maryland \\ ${ }^{+}$NASA Goddard Space Flight Center, Greenbelt, Maryland \\ \# Department of Physics, University of Idaho, Moscow, Idaho \\ ${ }^{\circledR}$ Space Science Institute, Boulder, Colorado \\ \& Department of Geological Sciences, Brigham Young University, Provo, Utah \\ ** University of Wisconsin-Madison, Madison, Wisconsin
}

(Manuscript received 7 April 2011, in final form 11 August 2011)

\begin{abstract}
Three decades of weather records at meteorological stations near Death Valley National Park are analyzed in an attempt to gauge the frequency of conditions that might form and erase the famous trails of wind-blown rocks in the mud of Racetrack Playa. Trail formation requires the playa to be wet, followed by strong winds and/or freezing conditions. Weather records are compared with a limited set of meteorological data that were acquired in situ at the playa over three winters and that indicate freezing on 50,29, and 15 nights during the winters of 2007/08-09/10, respectively, as well as with the hydrological condition of the playa as determined by time-lapse cameras that observed flooding over $\sim 1, \sim 5$, and $\sim 40$ days, respectively, during those winters. Measurements at the nearby Panamint and Hunter Mountain stations are found to be a useful, if imperfect $(\sim 50 \%)$, indicator of Racetrack Playa conditions and give some features of Racetrack Playa's micrometeorological behavior. Wind speed probability distributions suggest that winds that are fast enough to cause unassisted rock motion are rare and therefore that freezing of water on the playa has a role in a significant fraction of movement events.
\end{abstract}

\section{Introduction}

Racetrack Playa in Death Valley National Park, California, is a flat $4.5 \mathrm{~km} \times 2 \mathrm{~km}$ lake bed at an elevation of $1130 \mathrm{~m}$. It is of mixed sand-silt-clay composition, usually with striking but small regularly spaced dessication polygons of a uniform (buff) color. It is distinguished (e.g., Sharp and Carey 1976) by the presence of some dozens of rocks (usually cobbles or small boulders, but some up to $\sim 300 \mathrm{~kg}$ ) that are very distinct against the uniform playa (Fig. 1) and often appear at the end of trails or furrows in the playa surface. These trails suggest that the rocks have moved across the surface at some speed when the playa was wet and have been considered to be a "mystery" for which various scientific and nonscientific explanations have been proposed.

Corresponding author address: Ralph Lorenz, Space Dept., Applied Physics Laboratory, The Johns Hopkins University, 11100 Johns Hopkins Rd., Laurel, MD 21046.

E-mail: ralph.lorenz@jhuapl.edu
Much attention has been directed toward documenting the rocks and their movements (e.g., Kirk 1952; Sharp and Carey 1976; Reid et al. 1995; Messina 1998), and toward speculating upon the conditions under which they are induced to move, presumably by wind (e.g., Schumm 1956). The playa's isolated location (away from communications infrastructure as well as from habitation), however, and, more important, its deserved status as a site of extreme natural beauty (and more formally as a protected "wilderness" site within the national park) mean that there have been no systematic weather records acquired in the past at the playa itself. Therefore, useful data are lacking on which to base models of rock production (presumably by freeze-thaw action on dolomite cliffs at the south end of the playa, where most of the rocks are found) and their subsequent transport. This paper attempts to provide a quantitative basis for such studies by presenting relevant statistics from nearby weather stations that cover nearly three decades and showing, with a limited set of in situ data acquired at the playa with National Park Service permission, that these 


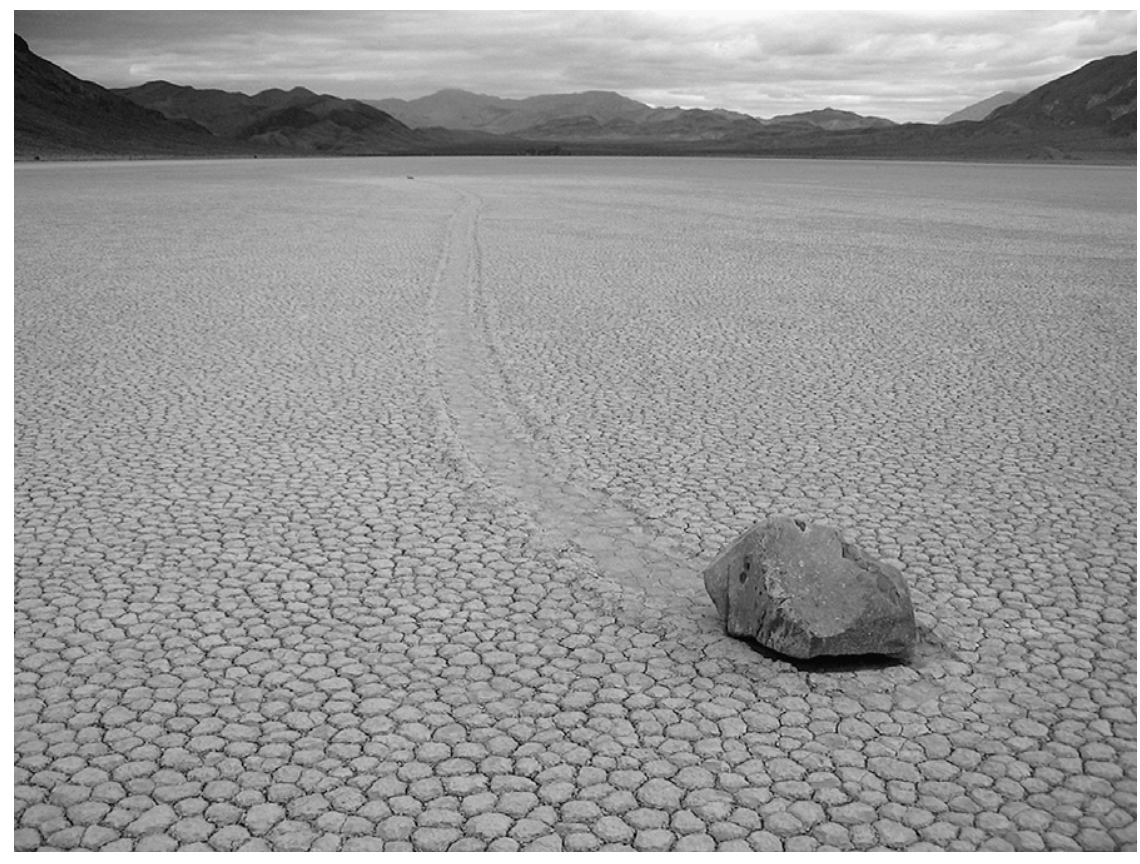

FIG. 1. A rock ( $\sim 15 \mathrm{~cm}$ high) with trail on Racetrack Playa. Note that the trail, which obliterates earlier desiccation cracks, has a slightly raised edge and termination, showing that the rock "bulldozed" the playa mud when it was soft.

regional stations are useful proxies for conditions at the playa itself.

\section{Meteorological variables of interest}

Three principal sets of data are of interest: precipitation, temperature, and wind. The need for precipitation knowledge is evident: the playa must be wet to soften the mud and permit the excavation of trails. It is important to consider temperature for several reasons. First, it seems likely that at least some episodes of rock movement take place when rocks are mechanically linked by a sheet of ice (since tracks, even with many turns, can be parallel to one another). Thus, data here can inform the debate (e.g., Reid et al. 1995) as to whether freezing is actually required (whether by enhancing the area over which wind drag can act or by floating rocks off the bed; Lorenz et al. 2011) for movement or only occasionally facilitates it. A second issue is that the rocks predominantly break off from the dolomite cliffs at the south end of the playa, and freeze-thaw cycling is a likely mechanism for their formation (e.g., Bland and Rolls 1998). In accord with these facts, the number of freeze-thaw cycles encountered at the playa is of interest in controlling the rock supply and, perhaps, also in controlling the ultimate destruction of the rocks. Air temperature also influences evaporation rate and thus the longevity of wetness on the playa.
Wind (and, in particular, peak wind) is of most interest but is the most challenging variable upon which to acquire useful insights. Messina and Stoffer (2000) investigate the role that the local steep topography around the playa may play in focusing the wind speeds and directions on the playa itself. Given that the gusts moving the rocks may be of very short duration, and indeed may be peculiar to the playa itself, the data from nearby sites will only serve as a guide. Because similar trails have been documented on several playas in the southwestern United States (Sharp and Carey 1976; Wehmeier 1986) as well as in South Africa (e.g., Eriksson et al. 1996), however, it is clear that, although they may be rare, rock-moving conditions are not unique to Racetrack Playa, and therefore nearby conditions may be a useful indicator.

Also, although the peak speeds recorded at nearby stations will only provide some guidance as to whether a given day had strong winds, the overall statistics of wind direction are important to understand the residence time of rocks on the playa in stochastic models of rock migration. Wind also influences evaporation rate and thus how long the playa stays wet after a precipitation event.

\section{Data}

We used daily summary Remote Automatic Weather Station (RAWS) data from the Western Regional Climate Center (obtained online at http://www.raws.dri.edu/wraws/ 
TABLE 1. Locations of Racetrack Playa, the RAWS stations, and other sites noted in this study. The distance column indicates the straight-line distance from the playa. For RAWS stations, the date at which records useful for this study begin is noted in the last column.

\begin{tabular}{|c|c|c|c|c|c|c|c|}
\hline & RAWS & Site & Lat $(\mathrm{N})$ & Lon $(\mathrm{W})$ & Elev $(\mathrm{m})$ & Distance $(\mathrm{km})$ & Data since \\
\hline 1 & & Racetrack & $36^{\circ} 41^{\prime}$ & $117^{\circ} 34^{\prime}$ & 1130 & & \\
\hline 2 & Yes & Oriental Wash & $37^{\circ} 14^{\prime}$ & $117^{\circ} 30^{\prime}$ & 1323 & 61 & Sep 1986 \\
\hline 3 & Yes & Hunter Mountain & $36^{\circ} 34^{\prime}$ & $117^{\circ} 28^{\prime}$ & 2219 & 16 & Feb 1989 \\
\hline 4 & Yes & Panamint & $36^{\circ} 7^{\prime}$ & $117^{\circ} 5^{\prime}$ & 2219 & 78 & Mar 1988 \\
\hline 5 & Yes & Horsethief Springs & $35^{\circ} 46^{\prime}$ & $115^{\circ} 54^{\prime}$ & 1613 & 189 & Sep 1991 \\
\hline 6 & Yes & Mojave River Sink & $35^{\circ} 3^{\prime}$ & $116^{\circ} 4^{\prime}$ & 306 & 231 & Mar 1990 \\
\hline 7 & Yes & Oak Creek & $36^{\circ} 51^{\prime}$ & $118^{\circ} 15^{\prime}$ & 1566 & 68 & Oct 1994 \\
\hline 8 & Yes & Opal Mountain & $35^{\circ} 9^{\prime}$ & $117^{\circ} 7^{\prime}$ & 1045 & 176 & Sep 1991 \\
\hline 9 & Yes & Indian Wells Canyon & $35^{\circ} 41^{\prime}$ & $117^{\circ} 53^{\prime}$ & 1290 & 115 & Feb 1996 \\
\hline 10 & & Furnace Creek & $36^{\circ} 28^{\prime}$ & $116^{\circ} 52^{\prime}$ & -61 & 71 & \\
\hline 11 & & Stovepipe Wells & $36^{\circ} 36^{\prime}$ & $117^{\circ} 8^{\prime}$ & 8 & 42 & \\
\hline 12 & & Wildrose & $36^{\circ} 16^{\prime}$ & $116^{\circ} 52^{\prime}$ & 1355 & 81 & \\
\hline
\end{tabular}

scaF.html). These stations, listed in Table 1, are operated by various agencies but most particularly by the U.S. Bureau of Land Management. The three stations nearest Racetrack Playa (Hunter Mountain, Oriental Wash, and Panamint at 16-, 61-, and 78-km distance, respectively) are examined in particular detail as proxies for Racetrack; the others are useful for identifying some trends, such as precipitation with altitude. Locations are identified in a regional topographic map in Fig. 2.

The RAWS data give a daily summary including average wind speed and direction, gust speed, air temperature (maximum, minimum, and average), relative humidity (maximum, minimum, and average), solar fluence $\left(\mathrm{kW} \mathrm{h} \mathrm{m}^{-2}\right)$, precipitation, and an estimate of Penman evaporation. The RAWS datasets vary in extent, with start dates from the mid-1980s to 1995 and running through the present. Data gaps exist, especially for solar fluence and winds and therefore also for the derived Penman evaporation. We take these gaps into account when computing our statistics.

There are additional weather stations in the area. Because their data records are generally much less complete and/or extensive, however, they are not considered here but are noted to facilitate studies by others. The nearly

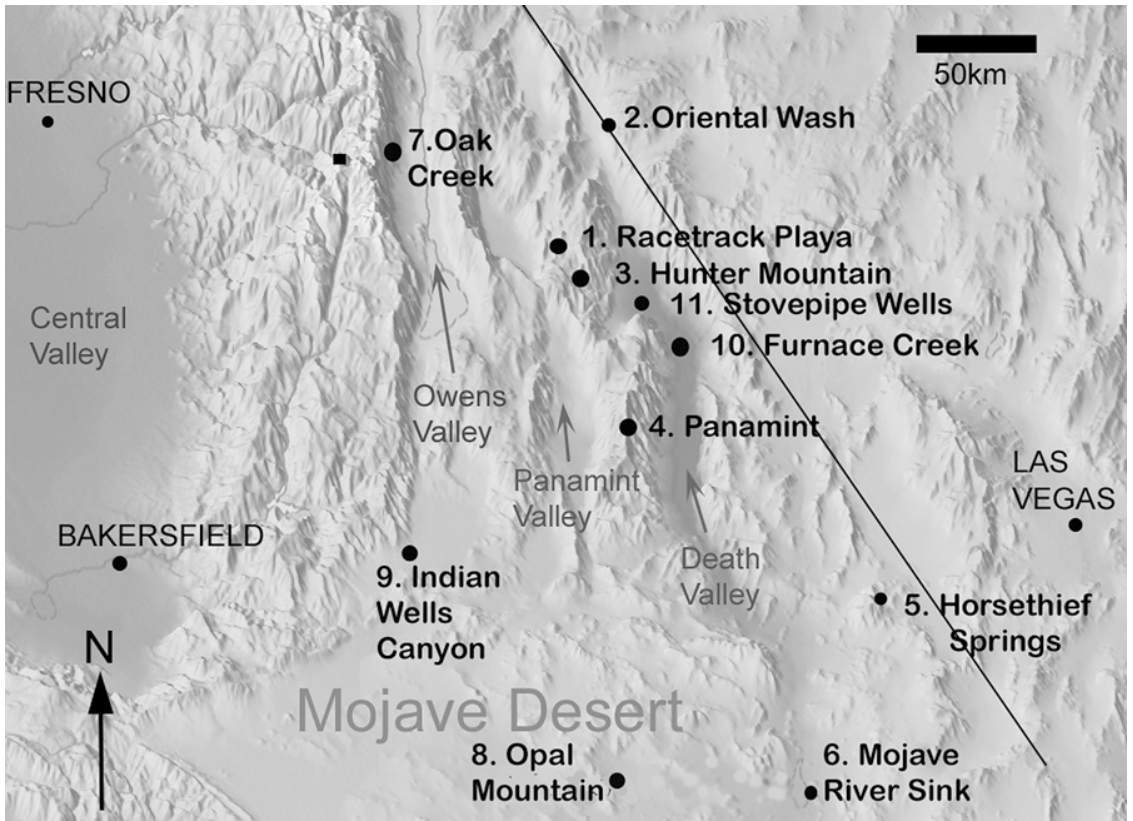

FIG. 2. Regional shaded relief map of the California-Nevada border area around Death Valley National Park, showing the location of the playa (1) and the RAWS stations studied here (2-9). The diagonal line denotes the state border, and several nearby cities and features are marked. 
century-long weather record at the resort at Furnace Creek has been discussed by Roof and Callaghan (2003), who give a useful overview of the climate of Death Valley (they also note that weather at the Wildrose ranger station was recorded during 1966-80, which may be of use for comparing with historical rock movements). There is a National Oceanic and Atmospheric Administration (NOAA) U.S. Climate Reference Network station at Stovepipe Wells (which is fairly close to Racetrack; see Fig. 2) for which current observations are made available online (http://www.ncdc.noaa.gov/crn/station.htm?stationId $=1105$ ); wind data at this station are not archived, however, and therefore it was not used in our study. Several personal weather stations, as well as those at airfields, are situated in the Ridgecrest-Inyokern-China Lake area (a selection may be viewed online at, e.g., www.wunderground.com), but, because these are very close to the Indian Wells Canyon RAWS site in our dataset, they yield little additional information.

\section{Results}

\section{a. Precipitation}

As is typical for the southwestern United States, the precipitation in our area of interest is zero for long periods of time, punctuated by occasional downpours. Rain can, of course, be highly localized; for example, Roof and Callagan (2003) report an occasion on which $3.8 \mathrm{~cm}$ of rain fell in 20 min at Cow Creek (the National Park Service offices), yet no rain was detected at Furnace Creek only $5 \mathrm{~km}$ to the south and at a similar elevation. As noted by Sharp and Carey (1976), much of the annual delivery of water to the playa is as snow in winter storms: precipitation in these frontal systems is typically less localized than in summer convective storms. This gives some hope that regional records are relevant for assessing conditions at Racetrack (especially since the rocks are believed to move most in winter). Figure 3 presents various statistics for the regional precipitation.

Figures $3 \mathrm{a}$ and $3 \mathrm{c}$ plot time series of precipitation records at Panamint and Hunter Mountain, the closest stations to Racetrack, although their micrometeorological settings may be different-notably the Hunter Mountain site is exposed while Panamint is sheltered on a hillside. It is seen (Fig. 3b) that precipitation in winter (defined here as between the autumn and spring equinoxes) generally exceeds that in summer. Individual events rarely exceed $40 \mathrm{~mm}$; a cumulative histogram for Panamint (Fig. 3d) shows that a couple of 20-mm events may occur in a typical year. Perhaps surprising is that there appears to be no strong El Niño signal in the data-a scatterplot (Fig. 3e) of rainfall at Panamint against the oceanic Niño index (ONI) derived from sea surface temperatures (SST) shows no obvious correlation (here we use the December-February NOAA ONI, version 3b, obtained online at http://www. cpc.noaa.gov/products/analysis_monitoring/ensostuff/ ensoyears.shtml). There appears to be some increase in rainfall with elevation (Fig. 3f) for the stations in our study, although the real dependence may in fact be greater than is shown here because the Mojave River Sink may have weaker terrain shadowing than the other sites. In reviewing all the data above, we find overall an expectation at Racetrack Playa of $80-100 \mathrm{~mm}$ of rainfall annually, biased toward winter, with no more than a few centimeters deposited in a single event.

\section{b. Temperatures}

Death Valley is justifiably famous for its dryness and high peak daytime temperatures (e.g., Roof and Callaghan 2003), but it also commonly experiences low winter temperatures. Further, the overall dryness means that the dryadiabatic lapse rate of $10 \mathrm{~K} \mathrm{~km}^{-1}$ (rather than a wet value of $\sim 5 \mathrm{~K} \mathrm{~km}^{-1}$ ) applies, and thus elevated areas have even colder conditions than might otherwise be expected. The relatively high elevation of Racetrack $(1130 \mathrm{~m})$ when compared with other playa deposits in the park, which do not typically freeze, is notable in this respect. The average temperatures are not of especial interest in this study, but the number of occasions on which freezing occurs is, both for considering the probability of the flooded playa freezing over, and for controlling the freeze-thaw production and destruction of rocks.

Figure 4 shows the average number of nights per year that the various stations experience freezing conditions-a trend with altitude is seen, with the number of freezing nights increasing from 10-20 at elevations of $1500 \mathrm{~m}$ and below to 50-100 nights above $2000 \mathrm{~m}$. Assuming Racetrack Playa is typical of the region, we would expect to see a few tens of freezing nights per year (i.e., where the minimum temperature is below zero), with perhaps a few days on which the maximum temperature never exceeds zero. However, freezing conditions are controlled substantially by the micrometeorological conditions of a given site, and the playa likely has freezing conditions more frequently than this trend would indicate (as indeed we ourselves measure in situ at the playa-see below). First, the large solid angle of cold, clear desert sky seen from a location on the playa allows it to cool effectively by radiation at night. On the other hand, terrain obstruction to the south - the cliffs from which most of the rocks are sourced-reduces the amount of direct sunlight available to warm the surface during the day, especially at the south end of the playa where most tracks are observed. Further, the local topographic minimum acts as a sump for cold air [an extreme example of which, reaching record temperatures of $-56^{\circ} \mathrm{C}$, is the 

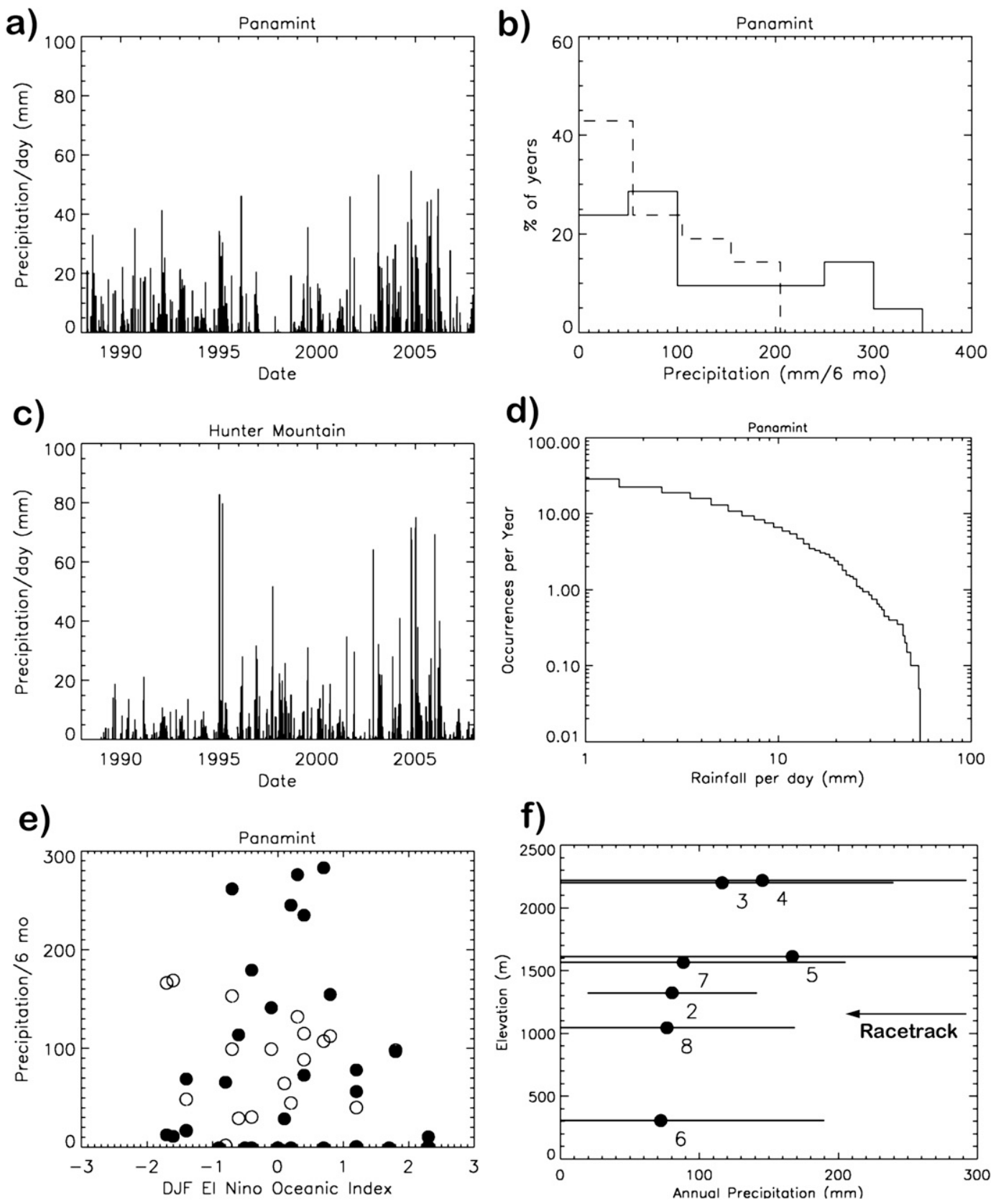

FIG. 3. Precipitation recorded at the RAWS sites. (a) Time series of precipitation at Panamint. (b) Histogram of the same data summed into 6-month intervals-the dashed line shows summer (April-September) and the solid line is winter (October-March). Summer precipitation is generally weaker. (c) As in (a), but for the Hunter Mountain station for comparison. (d) Cumulative histogram of events in (a), showing the expectation of maximum rainfall in an individual event. (e) Scatterplot of summer (open circles) and winter (filled circles) precipitation against the December-February ONI (see text); no strong correlation is evident. (f) Mean (circles) precipitation at the RAWS sites as a function of elevation: bars show 1 standard deviation, and the numbers are the station identifiers from Table 1. Note that Mojave River Sink (6) is less topographically shadowed than the others and so has higher rainfall than the overall precipitation-altitude trend might suggest.

1-km-wide Peter Sinks basin in Utah; see Clements et al. (2003)], which is likely the explanation for the deviation of Mojave River Sink (station 6) from the trend in Fig. 4.

\section{c. Winds}

A central question in developing models of rock movement is the likelihood of winds of various speeds. 


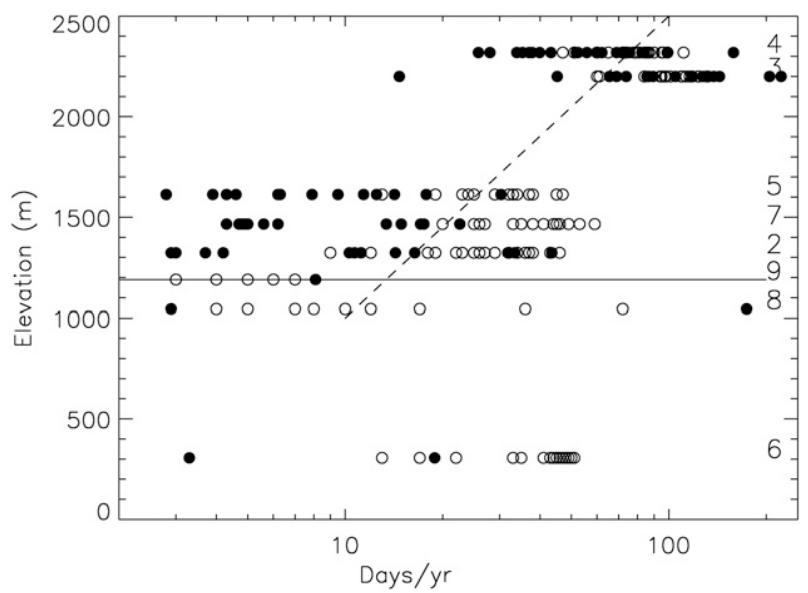

FIG. 4. Freezing at the RAWS sites. The solid horizontal line shows the elevation of Racetrack Playa. Open circles denote number of nights per year on which temperatures drop below freezingconsiderable year-to-year scatter is evident. Solid circles represent the negative degree-days per year of average temperatures, which may be a better indicator for growth of ice. The dashed line is a heuristic $\times 10$-per-1500-m line to guide the eye (not a formal fit). Numbers at right identify the sites (see Table 1 ). The large number of freezing days at site 6 (Mojave River Sink), despite its low elevation, attests to the significant role of micrometeorological effects.

Moving a $20-\mathrm{cm}$ rock of $20 \mathrm{~kg}$ without the benefit of rafting or lubrication would require winds of $\sim 80 \mathrm{~m} \mathrm{~s}^{-1}$ (Reid et al. 1995), yet the frequency of such an occurrence has not been addressed in the geological literature by anything more than words like "unlikely" or anecdotes of handheld anemometer measurements taken during short visits to the playa. With the argument given earlier that, while the playa is "windy," there is little reason to think it is substantially more or less windy than other California and Nevada playas in the same basin and range province: a useful discussion of winds in the region is found in Laity (1987). Therefore, we can inform expectations of winds (exceptional and otherwise) by the statistics of nearby stations.

Figure 5 shows the cumulative distribution of wind gusts (maximum 10-s gust during each day) recorded over $20 \mathrm{yr}$ or more at nearby stations. It is seen that the distribution has two principal parts: a steep falloff as winds approach $20 \mathrm{~m} \mathrm{~s}^{-1}$ (which gusts occur on about $2 \%$ of days in this period) and then a much fatter tail of high-speed gusts, with a constant power-law slope, with gust occurrence falling off by a factor of 10 for every $40 \mathrm{~m} \mathrm{~s}^{-1}$ increment in gust value. Only four gusts of $80 \mathrm{~m} \mathrm{~s}^{-1}$ have been recorded over $22 \mathrm{yr}$ at the Panamint RAWS station, and considerably fewer have been recorded at the other sites. We consider these statistics against the frequency of documented rock movement in section 5 of this paper. We find that wet days are not dramatically gustier than dry days: on average peak gusts on wet days were $0.7-5.3 \mathrm{~m} \mathrm{~s}^{-1}$ (0.06-0.67 standard deviations) higher than those on dry days.

We plot wind rose data from the RAWS sites in Fig. 6. It can be seen that the winds are strongly affected by
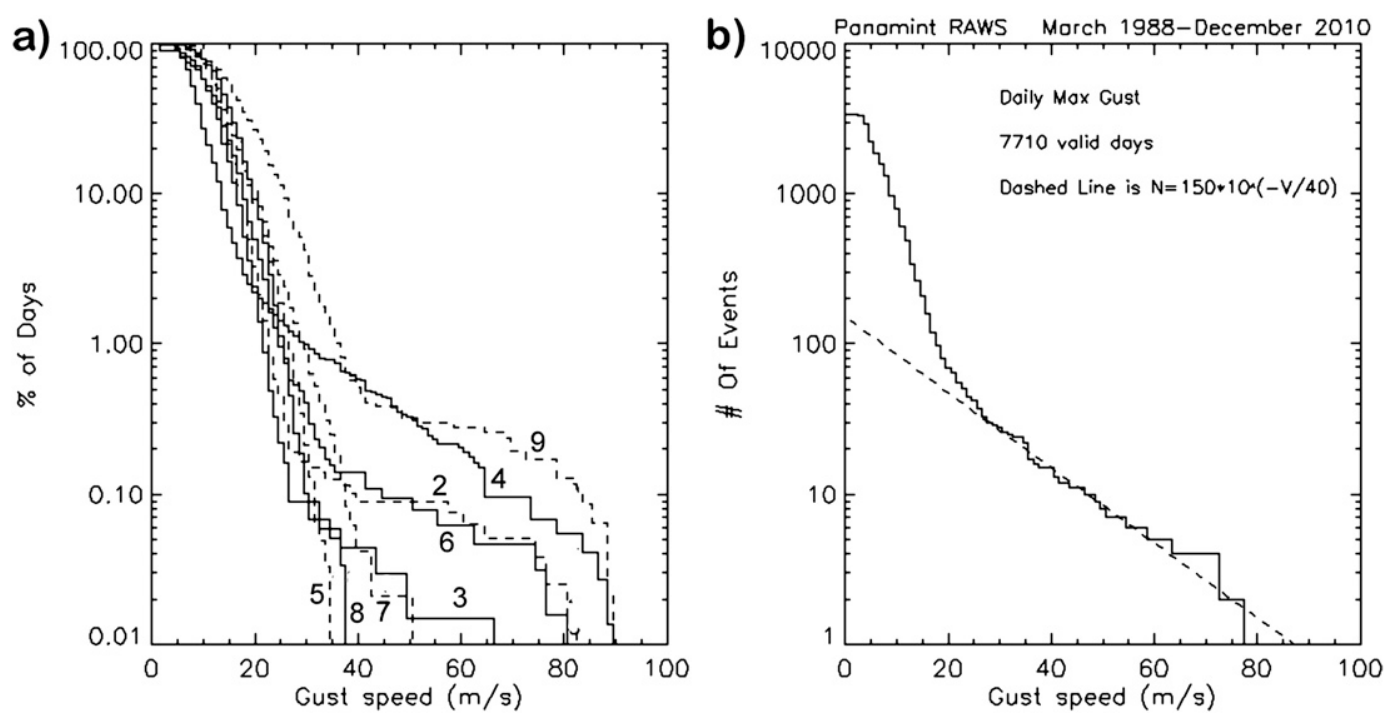

FIG. 5. (a) Wind gust statistics from the RAWS stations over 20 yr (cumulative count of maximum 10-s gust each day). Only the somewhat open (Fig. 2) Indian Wells site (9) has more frequent strong ( $>50 \mathrm{~m} \mathrm{~s}^{-1}$ ) gusts than Panamint (4). It is interesting that the Hunter Mountain site (3) lacks the long tail observed at Panamint and Indian Wells. (b) The Panamint distribution is composed of a steep falloff above $20 \mathrm{~m} \mathrm{~s}^{-1}$ and a shallower high-end tail that can be fit with a simple power law: $N=150 \times 10^{(-V / 40)}$, where $N$ is the number of events in the 12 -yr period and $V$ is in meters per second. 


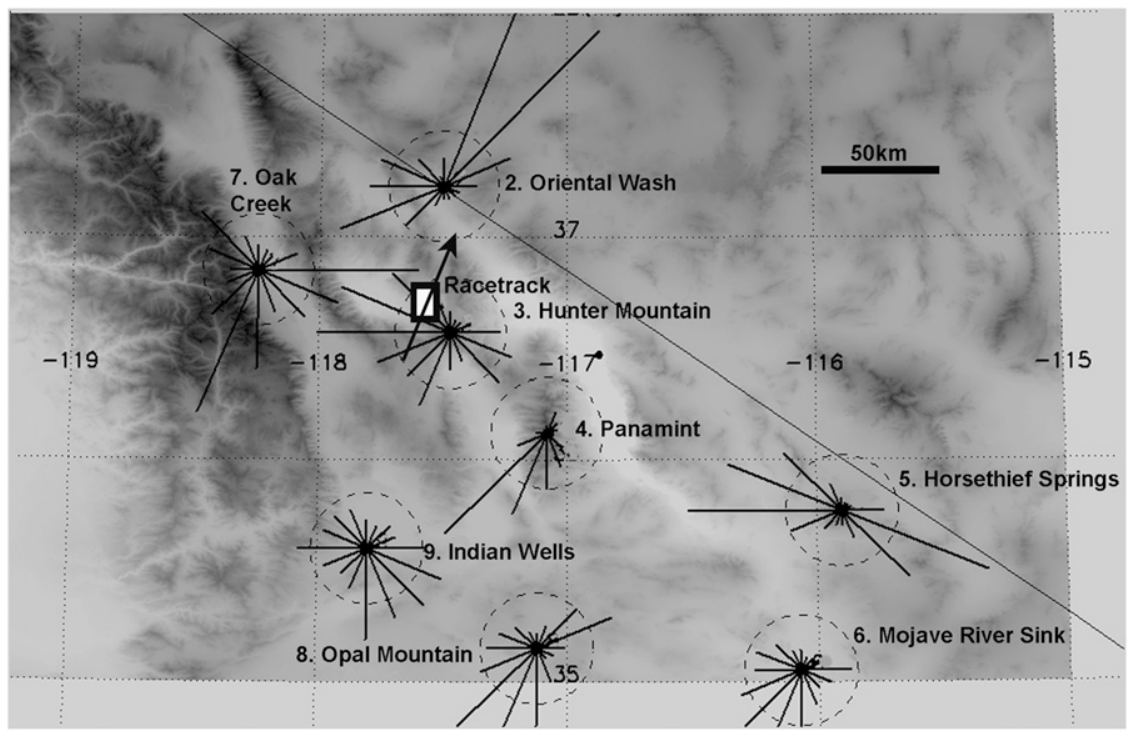

FIG. 6. Wind rose plots for the RAWS stations near the playa superimposed on a digital elevation model (a different representation of the shaded relief in Fig. 2): dark areas are high, and Death Valley is seen as a white sinuous line. Latitudes and longitudes are marked. Dashed circles on wind roses, where vector length corresponds to proportion of time from that direction, correspond to $10 \%$ of the time. The most obvious indication in the map is the control on wind direction exerted by local topography. It is seen also that overall there is a general bias for winds to come from the south. The apparent direction of most winds on Racetrack Playa (black/white rectangle) is shown by the arrow.

local topography. There is a general tendency to favor winds from the south, although a significant exception is the Oriental Wash site (site 2, the northernmost on the map) where winds often come from the northeast, entering the valley at that end and flowing south. In fact, it is well known that it is the convergence of this flow with the more general flow from the south that leads to the deposition of the sand to form the Mesquite dunes at Stovepipe Wells (e.g., Sharp and Glazner 1997).

It has been informally observed on our several visits to the playa that the wind has been mostly from the south to north, a pattern also noted by Messina (1998). The rock trails mapped by Messina, and documented by Reid et al. (1995), indicate predominant rock motion in a north-northeast direction, also supporting generally southerly winds. However, some trails indicating southward motion (northerly winds) have been seen by us, and are documented by Stanley (1955), showing that some transport occurs with northerly winds. An examination of the wind roses suggests that the proportion of southerly (south to north) to northerly winds at Racetrack Playa may be between 1:1 and 3:1, depending on which station is considered and whether only strong winds are included. Lacking a long-term wind direction record in situ, we suggest models of rock transport consider this range of values.

\section{In situ measurements}

\section{a. Meteorological instrumentation}

As part of a National Aeronautics and Space Administration (NASA) development program in eventtriggered meteorological systems (for studying dust devils), we installed compact instrumentation for trials at the playa: a requirement of this study (Study DEVA00169) was that the instrumentation not degrade the visual appearance of the playa, which is of course a major tourist attraction. Therefore, the equipment had to be essentially invisible, precluding large equipment boxes, meteorological masts, and so on. It furthermore could not be left on the playa itself but was installed at locations immediately adjacent to it. An aerial view of the playa, together with approximate observation sites, is shown in Fig. 7.

A datalogger, using a Basic Stamp IIe microcontroller (Parallax, Inc.) to record air temperature and humidity (Sensirion, Inc., SHT-11 sensor) at 15-min intervals, was installed for three winters during 2007-10 (Table 2) in the cliffs at the south end of the playa (location A in Fig. 7), about $20 \mathrm{~m}$ above the playa floor. This unit was powered by AA alkaline battery cells in a black plastic box measuring $5 \mathrm{~cm} \times 7 \mathrm{~cm} \times 15 \mathrm{~cm}$, and data were downloaded by means of a serial cable after recovery. In 2008 similar data from smaller commercial units 


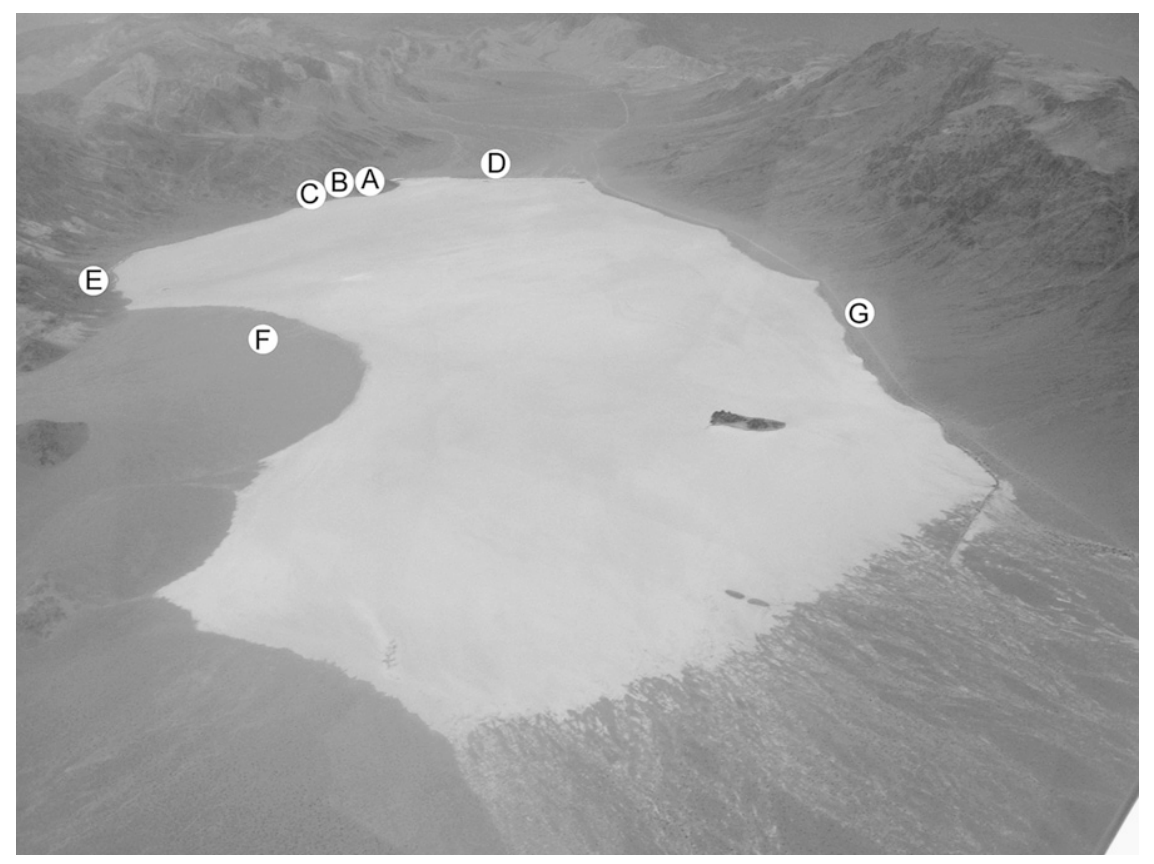

FIG. 7. Aerial view of Racetrack Playa, looking toward the south (photograph taken by first author). Letters denote measurement sites described in the text. The dark lump toward the lower right of the playa is the rock outcrop known as The Grandstand.

(Measurement Computing Corporation USB-501: $0.1^{\circ} \mathrm{C}$ precision and $1^{\circ} \mathrm{C}$ accuracy), roughly the size and shape of a marker pen and with a built-in USB connector, were obtained in several other locations (B, C, D, and G).

Another datalogger, using Picaxe-18X microcontrollers (Revolution Education, Ltd.), was installed near the eastern midedge of the playa (location E), well away from the most-frequented areas. In addition to recording the temperature of the case (arguably a better proxy for the playa surface temperature than that of the air) and light levels, these instruments measured the wind speed recorded by a cup anemometer (Inspeed, Inc.). To avoid any visual impact and thus to comply with our National Park Service permit conditions, the anemometer was mounted in scrub adjacent to the playa, on a mast only $20 \mathrm{~cm}$ above the ground, and was sprayed with a sandtextured paint to minimize visual impact. It is recognized that this low installation height places the anemometer within the surface layer (i.e., what aerodynamicists would call the boundary layer). We have intercalibrated this installation and a site of similar apparent aerodynamic roughness on an alluvial fan (location F) against handheld anemometers at the same spot and a temporary tripod installation on the playa itself: doubling the reading of the near-ground anemometer logger in the scrub brings it into close agreement with measurements at $\sim 2 \mathrm{~m}$ on the playa (which we found in separate measurements with a dual-anemometer setup on a tripod to be $\sim 25 \%$ higher than measurements at $25 \mathrm{~cm}$ on the playa-the low aerodynamic roughness of playas is well known). We recognize that the boundary layer correction will be dependent upon wind direction (which is not measured) and that therefore the record is not as faithful as one would hope. The setup is adequate for its principal goal, however, which is to determine whether the winds at the playa are somehow exceptional.

Although the anemometer datalogger was installed for three winters during 2007-10, only one good record was obtained: over the winter 2008/09. Two difficulties prevented a fuller return of data. First, the cable connecting the diecast datalogger box to the anemometer was found to have been broken in about 20 places when the unit

TABLE 2. Measurement campaigns and Playa conditions documented by time-lapse cameras. The asterisk indicates freezing.

\begin{tabular}{clll}
\hline \hline Deployment & \multicolumn{1}{c}{ Light sheen (frost or dampness) } & \multicolumn{1}{c}{ Flooded } \\
\hline 28 Nov 2007-3 Mar 2008 & 7 Dec; 9 Dec; 4 Jan; 5 Jan; 23 Jan; 26 Jan & 8 Dec & Snow \\
3 Dec 2008-3 Mar 2009 & 15 Dec; 7 Feb; 9 Feb; 16 Feb & 10-14 Feb; 15 Feb* & 9 Feb \\
5 Nov 2009-3 Dec 2010 & 16-17 Jan & 25 Jan-26 Feb & 19-24 Jan; 3 Mar \\
\hline
\end{tabular}


was recovered in March of 2008-apparently a packrat or similar rodent had chewed it. In subsequent winters we buried the cable to the extent possible under a couple of centimeters of dirt, and no cable failures have been since noted. Second, although the logger casing was secure against rainfall, it seems that during the winter of 2009/10 the water level in the playa-probably deepened locally and temporarily by wind setup-was enough $(\sim 40 \mathrm{~cm}$ above the playa edge) to completely submerge it; when the unit was recovered, it was found to be full of water (an ironic fate given the reputation of Death Valley for heat and dryness).

\section{b. Time-lapse camera observations}

The hydrological state of the playa was determined over three winters by digital time-lapse cameras installed in the mountains above the playa. Digital time-lapse cameras with flash memory permit the battery-powered acquisition of thousands of images over periods of months. As with the meteorological instrumentation, these cameras [see Lorenz et al. (2010a) for details] were deployed in an inobtrusive manner to comply with study regulations (and to minimize the chance of theft or vandalism: in fact, one camera was lost in 2010).

Most of the images, of course, show the same barren, empty playa. One interesting observation is from the early afternoon of $\sim 23$ January 2009 (Fig. 8a) and shows a dust devil, which is remarkable because dust-devil activity is usually associated with summer. The appearance of the playa changes dramatically on a few occasions in winter, however, becoming covered in snow, which subsequently melts to form a transient lake that can have a mirrorlike smoothness (not unlike, apparently, the Racetrack-shaped Ontario Lacus on Saturn's moon Titan; see Lorenz et al. 2010b; Wye et al. 2009), can be muddy and wind rippled, or can be frozen [see image sequence in Lorenz et al. (2010a)]. One other aspect of the playa hydrological behavior is that the shallow but extensive puddle of water can be blown from one end of the lake bed to the other-wind stress is able to overcome the near-zero topographic gradient, which usually causes the water to pool at the south or east parts of the playa. Figures $8 \mathrm{~b}$ and $8 \mathrm{c}$ show the water at the middle and the south of the playa, respectively. Key aspects of the playa state over the three winters of observation are summarized in Table 2: dates may be approximate, because some of the cameras lack time stamps and take a slightly nondeterministic number of images per day (since they depend on light levels); therefore, dates have to be estimated from the apparent diurnal cycle in the image sequence. A camera also ran from March to October of 2010 and, apart from one brief spring dusting of snow, indicated no further precipitation over that period. One final remark on the imaging is that it is evident (as a raytracing topographic analysis would show) that parts of the playa are in shadow for several hours during the winter-in particular, at the south end of the playa.

\section{c. Interpretation of in situ data}

Sharp and Carey (1976) state, without offering supporting data, that Racetrack Playa temperatures often drop below freezing. Our in situ measurements allow quantification of this assertion-the temperature record (Fig. 9) shows that air temperatures dropped below $0^{\circ} \mathrm{C}$ on 50, 29, and 15 nights during the three winters observed, which is consistent with the expectations from the playa elevation (Fig. 4). Although not in a conventional louvered Stevenson screen or similar housing, the datalogger was protected from direct sunlight and precipitation. The data suggest substantial freeze-thaw cycling, which is likely a major factor (e.g., Goudie 1995) in the production of rock splinters from the cliffs that eventually reach the playa to become moving rocks.

The USB-501 loggers at other locations show broadly similar temperature variations. Some notable differences are that the time at which temperatures rise steeply in the morning depends on location, because of shadowing by the adjacent mountains. Also, even with a broadly similar setting in the cliffs at B and similar maximum temperatures, a logger that was closer to the playa (just a few meters away) shows somewhat lower nighttime temperatures (by $2^{\circ}-3^{\circ} \mathrm{C}$ ) than that at A described above: a likely explanation-assuming that the $1^{\circ} \mathrm{C}$ accuracy specification on the devices holds-is that of cold-air pooling in the playa on calm nights. Even-lower temperatures are encountered on surfaces, as shown by a temperature sensor mounted on the diecast box of the anemometer datalogger at E, which, adjacent to the playa, saw a large solid angle of sky. On a cold night (e.g., 31 December 2008), while the logger at A recorded a minimum temperature of $-1.1^{\circ} \mathrm{C}$ and the USB unit at $\mathrm{B}$ reached $-3.9^{\circ} \mathrm{C}$, the anemometer box (perhaps a reasonable proxy for the temperature of a small rock on the playa) fell to $-8^{\circ} \mathrm{C}$.

The anemometer logger recorded the maximum 5-s gust each hour over the winter of 2008/09. These data are shown in Fig. 10, together with a correlation with the maximum gust per day at the Panamint RAWS site. Although the scatter is significant, there is some agreement (correlation coefficient squared $r^{2}=0.51$ ). Although histograms (Figs. 10c,d) show that in formal terms (a Kolmogorov-Smirnov tests fails) the Racetrack and Panamint wind measurements are not from exactly the same distribution, the maximum values encountered are the same and the populations are overall similar (albeit with far fewer data than for the $20 \mathrm{yr}$ of RAWS records in 

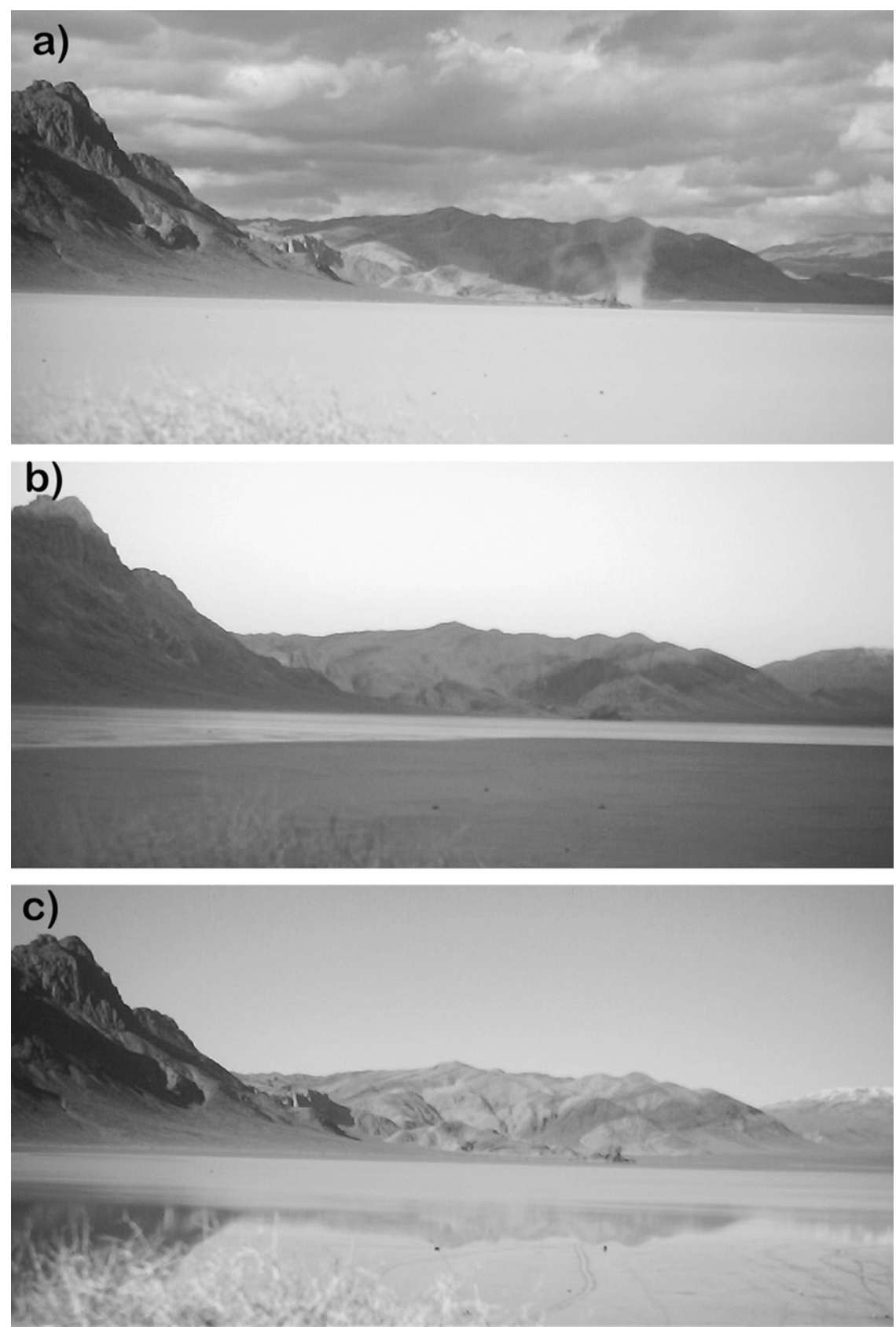

FIG. 8. A set of time-lapse images acquired in 2009 from station C in Fig. 7, looking north, showing the hydrologically dynamic conditions on the playa. (a) The dry playa, with a dust devil just to right of center-remarkable given that this image was taken circa 23 Jan. (b) Wet and frozen conditions at the end of January, with the water confined to the left distance. (c) Two days earlier, the water is seen in the foreground and reflects the mountains except in the middle distance where wind is ruffling the water surface.

Fig. 5) to the other sites. Therefore, it seems plausible to use RAWS data as at least an indicator of the frequency of occurrence of larger gusts, and claims that Racetrack may see exceptionally strong winds do not appear to be justified.

\section{d. Relationship of regional precipitation with conditions on the playa}

A principal objective of this paper is to determine whether readily available online meteorological data can 

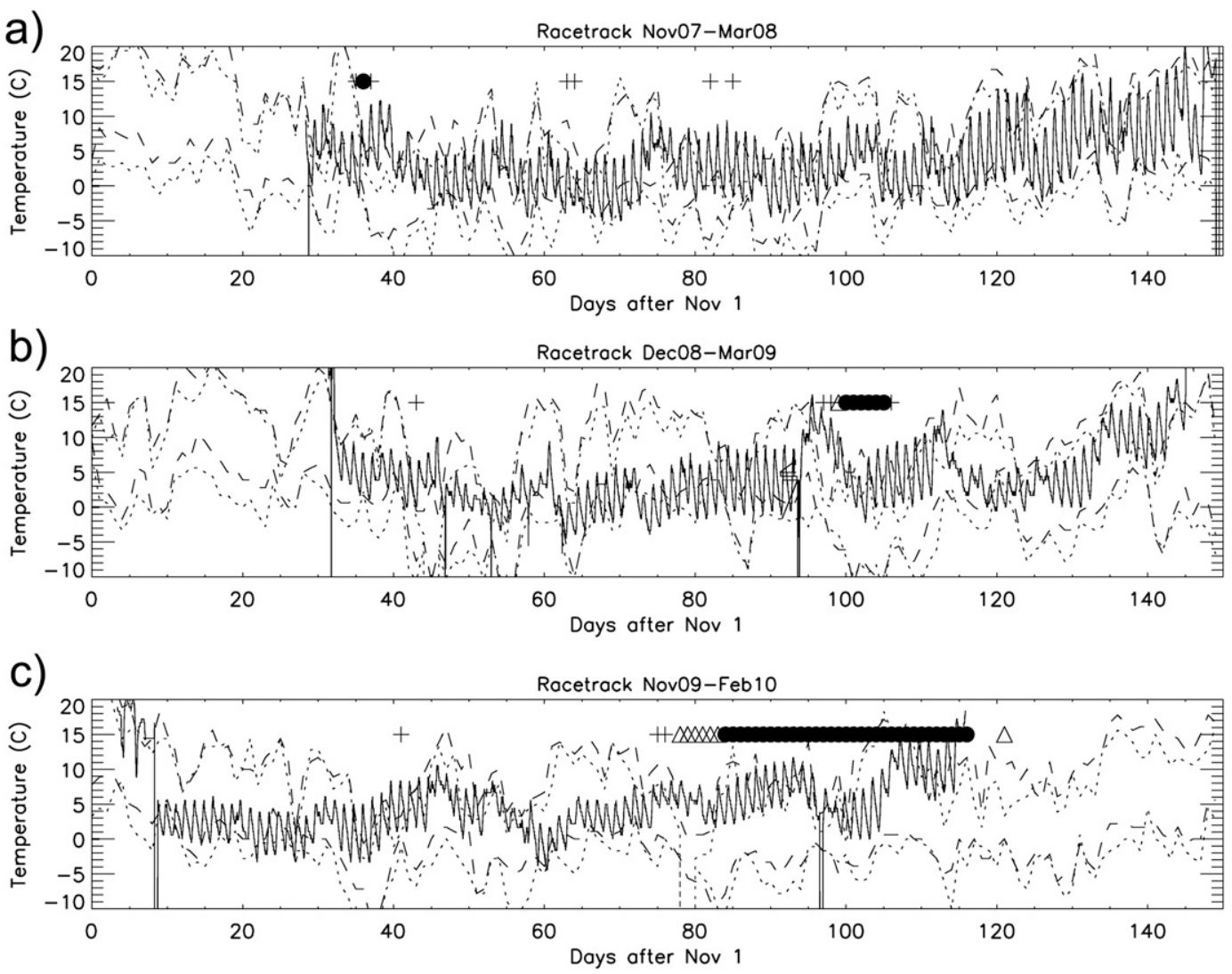

FIG. 9. Time series of temperature measurements at the playa made over three winters. Sets of dotted and dashed lines are the daily minimum and maximum temperatures from Panamint and Hunter Mountain, respectively. Crosses at the top of the graph indicate occasions on which a trace of water or snow is visible, triangles are snow cover, and the filled circles (forming a solid bar) denote that the playa is flooded.

provide an indication of conditions at the playa. For the purpose of enabling rock movement, of interest is the length of time for which the playa remains wet (and thus slippery). As a crude metric, we take the daily precipitation records for the RAWS stations, and, when an event occurs, we set the depth of water on the playa to that value, then progressively decrement the depth by the daily Penman evaporation computed in the RAWS record, until the depth becomes zero. This procedure must be considered as only a guide, since the playa water depth may exceed the precipitation by a factor of a few because of the larger catchment area that drains into the playa (with some uncertain amount of infiltration into the soil), and winds and thus the resultant evaporation rate at the playa may differ from any given site.

Figure 11 shows some example results. It is seen that the skill of an estimator that is based on the approach above (multiplying the evaporation rate by an empirical factor $F=3$ ) appears to be about $50 \%$ : although Racetrack can be wet when a model based on Panamint data (or any other station) suggests it should not be, about one-half of the time the model agrees with observations. With this caveat in mind, an analysis of the fuller RAWS datasets (not shown) suggests that the probability of encountering an event in which the playa remains wet for $N$ days is approximately $1 / N$. We have additionally examined the correlation between the precipitation records at the various RAWS sites-in general, for $40 \%-50 \%$ of the days on which the precipitation is nonzero at one site it is nonzero at the other. This correlation increases to $\sim 60 \%-70 \%$ if the records are smoothed with a 2-day boxcar filter (such that on $\sim 65 \%$ of days that one site has rain the other site has rain within 2 days). Therefore, although localized events of course occur, the precipitation in this area is largely due to regional storms that affect many sites, and thus Racetrack conditions should be correlated with the RAWS sites.

\section{Conditions for rock movement}

We unfortunately have not observed widespread rock movement or trail formation during our measurement 

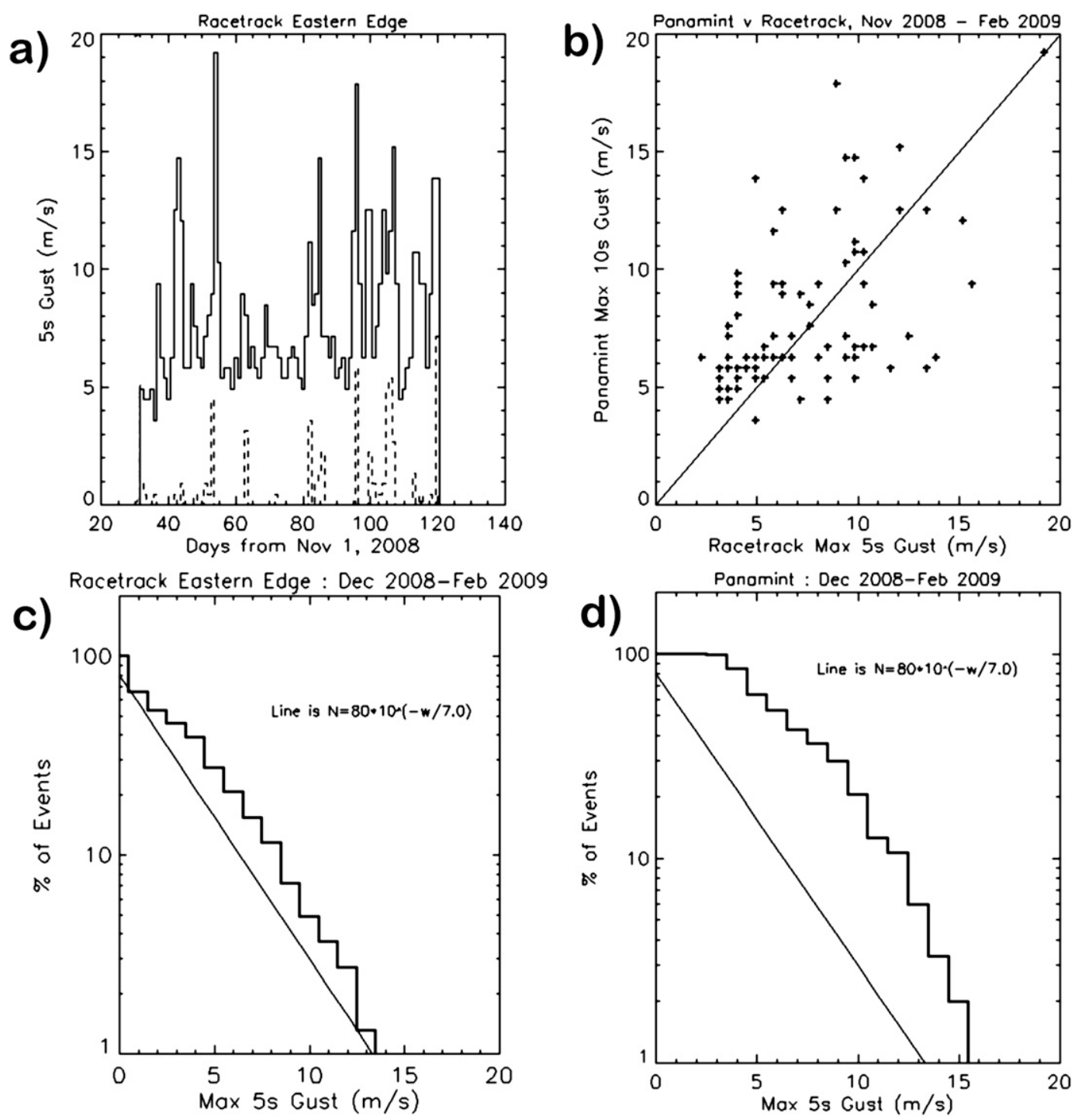

FIG. 10. Wind measurements at the playa (E) over the winter of $2008 / 09$, corrected by $\times 2$ for boundary layer effects. (a) Time series of daily strongest (solid line) and weakest (dashed line) gusts per hour; nonzero values of the latter imply the wind never fell to zero. (b) Correlation of maximum daily gust from the playa station against the Panamint RAWS maximum daily gust — despite the scatter, the correlation is encouraging (note that the line is a 1:1 relationship and not a fit). (c),(d) Differential histogram of hourly wind gusts: steep falloff resembles that of the RAWS stations (Fig. 5); observations are over too short of a period to permit probable detection of large gusts.

campaign. We can consider historical observations, however. Reid et al. (1995) note two major movement events: one in the late 1980s and another in late 1992 or early 1993. The largest rocks on the playa moved in the 1980s event, leaving deeply furrowed tracks with pronounced levees (still $\sim 8 \mathrm{~mm}$ high in 1994), but did not move in the 1992/93 event. Nearby weather conditions are documented at Hunter Mountain and Panamint during the 1992/93 winter. The data unfortunately do not provide a major discrimination between the two principal hypotheses of rock movement. First, the Panamint record shows gusts of $20 \mathrm{~m} \mathrm{~s}^{-1}$ and above on 5 days between November and March, of which two were $\sim 35 \mathrm{~m} \mathrm{~s}^{-1}$. A couple of $25 \mathrm{~m} \mathrm{~s}^{-1}$ gusts and one $35 \mathrm{~m} \mathrm{~s}^{-1}$ gust $(10$ December) occur on days during or shortly after days on which precipitation was recorded. A $72 \mathrm{~m} \mathrm{~s}^{-1}$ gust was recorded on 3 December, before any precipitation occurred (and therefore, although it might move rocks, it would not form trails). On the other hand, around 10 January 1993, a couple of days after recording $\sim 10 \mathrm{~mm}$ of precipitation, the Hunter Mountain station (at which winds were not recorded) experienced five consecutive 
a)

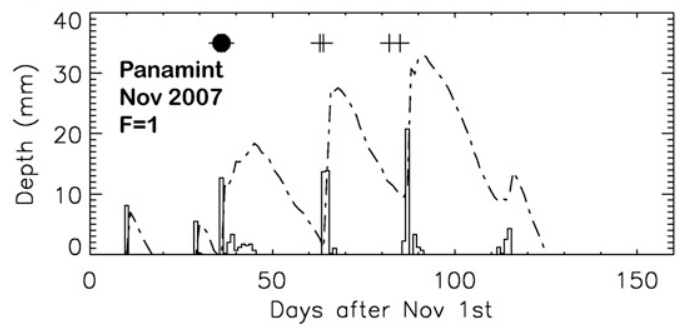

b)

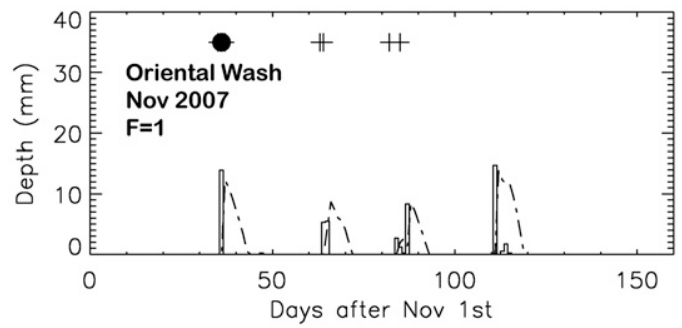

c)

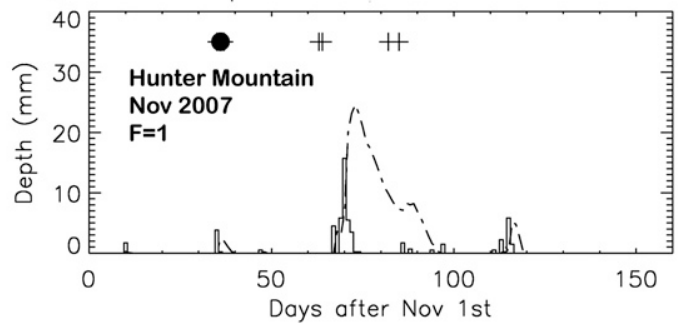

d)

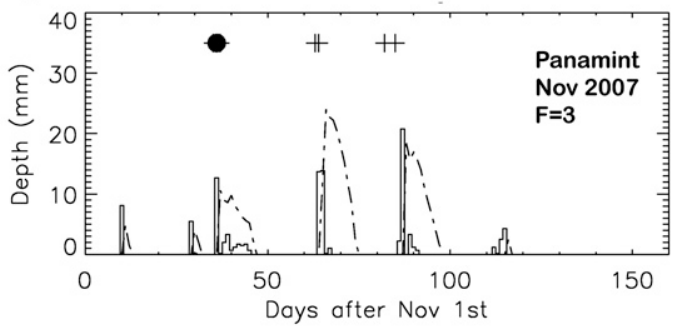

e)

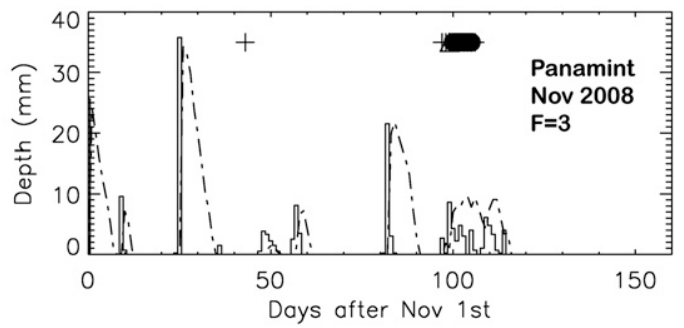

f)

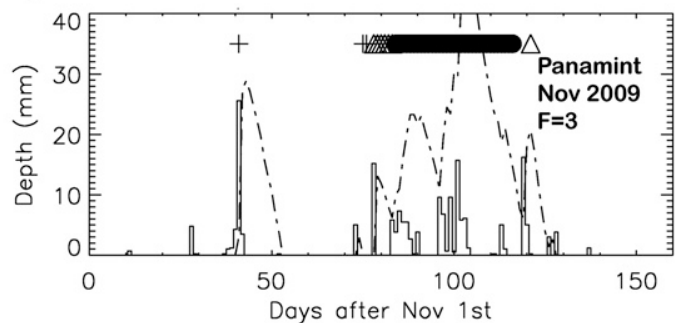

FIG. 11. Precipitation at RAWS stations (solid line), and running estimate of surface water depth obtained by incrementing by daily precipitation and decrementing by RAWS Penman evaporation estimate multiplied by an arbitrary factor $F$. Bars at the top of the plot denote playa flooding as determined by time-lapse cameras (as in Fig. 9). (left) The three RAWS stations (Panamint, Oriental Wash, and Hunter Mountain) during 2007/08 with $F=1$, showing the correlations among several locations. Use of $F=1$ yields typically 10 days of estimated flooding per event, which appears to be excessive. (right) Panamint over the three winters with $F=3$, yielding better estimates of flooding duration. Note the long flooding episode in (f) during 2009/10, and the reasonable estimation of the duration with $F=3$.

days during which air temperatures never rose above freezing. It is reasonable to suppose that ice of some thickness might grow. Thus, it seems for the Reid et al. (1995) event in 1992/93 that conditions might have (to be charitable) permitted movement to occur without freezing but were perhaps more likely facilitated by ice.

Sharp and Carey (1976), in a more permissive era, marked a number of stones and recorded their positions relative to marker stakes. They suggested that large-scale rock movements might occur every $2-3$ yr, noting movement of 10 or more stones in the winters of 1968/69, 1972/ 73 , and 1973/74. No movement occurred during 1974/75, and only three stones moved during 1970/71. These observations unfortunately predate the installation of automated weather stations in the area, and therefore we cannot correlate the events with specific conditions. We can, however, compare their movement frequency estimate with our weather statistics (making the assumption-which could be called into question-that conditions in the 1960s and 1970s are not too different from those of the 1980s to the present).

The Panamint RAWS gust statistics suggest that in any one year one might expect about one gust of $50 \mathrm{~m} \mathrm{~s}^{-1}$ and five gusts of $20 \mathrm{~m} \mathrm{~s}^{-1}$, with frequency increasing sharply for weaker winds. We have observed that the playa has been wet for $\sim 1, \sim 5$, and $\sim 40$ days during the winters of 2007/08, 2008/09, and 2009/10, respectively. A rough estimate, then, is of $\sim 10$ days of flooding per year, or $\sim 1 / 30$ th of a year. Thus, for one random wind gust (assuming that wind gusts that occur some days after precipitation have statistics that are similar to those for the whole year, though see section 4c) to have a reasonable probability of occurring when the playa is flooded, a gust of that magnitude should happen $>\sim 30$ times per 
year. This appears to rule out winds higher than about 15$20 \mathrm{~m} \mathrm{~s}^{-1}$. Because field measurements of the friction of even wet (and apparently slippery) mud against rocks (Reid et al. 1995; Lorenz et al. 2010a) suggest that winds of $60 \mathrm{~m} \mathrm{~s}^{-1}$ would be needed to move typical rocks (winds that occur about once per year), the joint probability of a $60 \mathrm{~m} \mathrm{~s}^{-1}$ gust and a flooded playa yields a frequency of rock movement of only once in $\sim 30 \mathrm{yr}$, which is lower than is observed.

With regard to freezing, the time-lapse imagery shows that the flooded playa indeed can freeze over (as the rockless tracks sometimes found on the playa, apparently formed by wind-blown sheets of ice, also attest). Occurrences of once per year or two to several nights per year seem consistent with the few tens of nights of freezing conditions we have documented, convolved with the number of flooded days we have estimated above. Not all freezing nights will be enough to generate ice thicknesses large enough to raft rocks, and a fuller analysis is beyond the scope of this paper, but the probabilities associated with ice and modest gusts together seem more encouraging than those of wetness and strong gusts.

\section{Conclusions}

We have reviewed data from meteorological stations near Racetrack Playa, Death Valley National Park, and compared them with a limited set of in situ data. The data presented here bring a quantitative foundation upon which to build models of rock production and movement. We have developed the following conclusions. First, modern instrumentation and time-lapse cameras can provide useful insights into conditions at the playa, without compromising its visual appeal.

Second, although the playa is visually an exceptional location, its meteorological situation appears not to be significantly different from elsewhere in the region at similar elevations, although cold-air pooling and shadowing may locally reduce temperatures. We have documented temperatures, winds, and the snow- or water-covered state of the playa over three winters, and these conditions appear to be consistent with indications from regularly monitored sites a few tens of kilometers away. Some tens of freezing nights, and about $90 \mathrm{~mm}$ of precipitation, are encountered per year. That precipitation is deposited at most $\sim 40 \mathrm{~mm}$ at a time and results in flooding of the playa from 1 to $\sim 30$ days per year. Precipitation data from nearby sites are a useful, but imperfect $(\sim 50 \%)$, indicator of whether the playa will be flooded. The oceanic Niño index does not appear to be a useful predictor of regional rainfall or of the playa conditions. Wind probability distributions at nearby sites appear to be consistent with the limited data at the playa and suggest that for rocks to move at the $\sim 3-4$ times per decade suggested by Sharp and Carey (1976) gusts of much less than $\sim 60 \mathrm{~m} \mathrm{~s}^{-1}$ must be generally responsible, suggesting that some lubrication, drag enhancement, or rafting by ice is often, if not always, involved. Winds are controlled largely by local topography, as noted by Messina and Stoffer (2000), but appear to be somewhat biased to a southerly direction.

It is our contention that understanding the conditions at the playa does not detract from the appeal of this remarkable place. Rather, investigations such as those reported here only serve to highlight what a particular and rare set of circumstances is required to allow rocks to move and to underscore that a changing climate may alter the frequency with which movements occur.

Acknowledgments. The datalogging and time-lapse experiments by RL were funded in part by the NASA Applied Information Systems Research (AISR) program, and other visits to the playa were supported in part by the Cassini Radar (RADAR) program. BJK acknowledges a research grant from the Geological Society of America and discretionary support from the director of the Lunar and Planetary Laboratory of The University of Arizona. We thank David Choi and Catherine Neish for assistance in the field. We are grateful for the assistance of David Ek, wilderness resources coordinator at Death Valley National Park, in conducting the in situ measurements. The authors gratefully acknowledge Cynthia Cheung and the NASA Lunar and Planetary Sciences Academy for support of the publication of this work. We thank three anonymous reviewers for their careful reading of the paper and for suggestions that led to its improvement.

\section{REFERENCES}

Bland, W., and D. Rolls, 1998: Weathering-An Introduction to the Scientific Principles. Oxford University Press, 288 pp.

Clements, C. B., C. D. Whiteman, and J. D. Hotel, 2003: Cold-airpool structure and evolution in a mountain basin: Peter Sinks, Utah. J. Appl. Meteor., 42, 752-768.

Eriksson, P. G., E. B. Fortsch, C. P. Snyman, J. H. Lingenfelder, B. E. Beukes, and W. Cloete, 1996: Wind-blown rocks and trails on a dry lake bed: An alternative hypothesis. J. Sediment. Res., 66, 36-38.

Goudie, A., 1995: The Changing Earth. Blackwell, 352 pp.

Kirk, L. G., 1952: Trails and rocks observed on a playa in Death Valley National Monument, California. J. Sediment. Petrol., 22, 173-181.

Laity, J. E., 1987: Topographic effects on ventifact development, Mojave Desert, California. Phys. Geogr., 8, 113-132.

Lorenz, R. D., B. Jackson, and J. W. Barnes, 2010a: Inexpensive time-lapse digital cameras for studying transient meteorological phenomena: Dust devils and playa flooding. J. Atmos. Oceanic Technol., 27, 246-256. 
, and A. Hayes, 2010b: Racetrack and Bonnie Claire: Southwestern U.S. playa lakes as analogs for Ontario Lacus, Titan. Planet. Space Sci., 58, 723-731.

_ , B. K. Jackson, J. W. Barnes, J. N. Spitale, and J. M. Keller, 2011: Ice rafts not sails: Floating the rocks at Racetrack Playa. Amer. J. Phys., 79, 37-42.

Messina, P., 1998: The sliding rocks of Racetrack Playa, Death Valley National Park, California: Physical and spatial influences on surface processes. Ph.D. thesis, City University of New York, 407 pp.

— , and P. Stoffer, 2000: Terrain analysis of the Racetrack basin and the sliding rocks of Death Valley. Geomorphology, 35, 253-265.

Reid, J. B., E. P. Bucklin, L. Copenagle, J. Kidder, S. M. Pack, P. J. Polissar, and M. J. Williams, 1995: Sliding rocks at the Racetrack, Death Valley: What makes them move? Geology, 23, 819-822.
Roof, S., and C. Callagan, 2003: The climate of Death Valley, California. Bull. Amer. Meteor. Soc., 84, 1725-1739.

Schumm, S. A., 1956: The movement of rocks by wind. J. Sediment. Petrol., 26, 284-286.

Sharp, R. P., and D. L. Carey, 1976: Sliding stones, Racetrack Playa, California. Geol. Soc. Amer. Bull., 87, 1704-1717.

_ , and A. F. Glazner, 1997: Geology Underfoot in Death Valley and Owens Valley. Mountain Press, 319 pp.

Stanley, G. M., 1955: Origin of playa stone tracks, Racetrack Playa, Inyo County, California. Geol. Soc. Amer. Bull., 66, 1329-1350.

Wehmeier, E., 1986: Water induced sliding of rocks on playas: Alkali Flat in Big Smoky Valley, Nevada. Catena, 13, 197-209.

Wye, L., H. Zebker, and R. Lorenz, 2009: Smoothness of Titan's Ontario Lacus: Constraints from Cassini RADAR specular reflection data. Geophys. Res. Lett., 36, L16201, doi:10.1029/ 2009GL039588. 
Copyright of Journal of Applied Meteorology \& Climatology is the property of American Meteorological Society and its content may not be copied or emailed to multiple sites or posted to a listserv without the copyright holder's express written permission. However, users may print, download, or email articles for individual use. 